\title{
Efeitos da umidade relativa do ar na incubadora e da idade da matriz leve sobre o rendimento da incubação
}

[Effects of relative air humidity in the hatchery and breeder hen age on the incubation yield]

\author{
V.M. Barbosa, S.V. Cançado*, N.C. Baião, A.M.Q. Lana, L.J.C. Lara, M.R. Souza \\ Escola de Veterinária - UFMG \\ Caixa Postal 567 \\ 30123-970 - Belo Horizonte, MG
}

\begin{abstract}
RESUMO
Avaliaram-se os efeitos da umidade relativa do ar na incubadora (URI) e da idade da matriz leve sobre o rendimento de incubação, sobre o peso absoluto do coração e do saco vitelino e sobre a relação desses dois órgãos com o peso do pinto ao nascer. Foram utilizados 10.836 ovos de matrizes da linhagem Lohmann LSL, com 26, 41 e 56 semanas de idade, incubados com níveis de URI de 48, 56 e 64\%. A perda de peso do ovo foi maior à medida que diminuiu a URI ou à medida que aumentou a idade da matriz. A maior taxa de eclosão foi obtida quando se utilizaram $56 \%$ de URI, e os ovos das matrizes mais velhas apresentaram eclodibilidade reduzida. A maior relação saco vitelino/peso do pinto foi obtida quando os ovos foram incubados com URI de $48 \%$ e com ovos de matrizes com idade de 41 semanas. Os pintos de matrizes com 41 e 56 semanas de idade apresentaram os maiores pesos absolutos do coração e os das matrizes com 56 semanas, a maior relação peso coração/peso pinto.
\end{abstract}

Palavras-chave: ave de postura, umidade relativa do ar, idade da matriz leve, incubação, taxa de eclosão

\begin{abstract}
The effects of hatchery relative air humidity (RAH) and age of breeder hen on incubation yield, on heart weight, on yolk sac and on the ratio of these organs and the newly-hatched chick weight were evaluated. A total of 10,836 eggs of Lohmann LSL of 26, 41 and 56 week-old breeder hens were incubated in three hatchery relative humidity (48, 56 and 64\%). Egg weight loss was higher for eggs incubated at lower $R A H$ and for older breeder hens. The hatchability was higher for RAH lower than $56 \%$ and lower for eggs of older hens. Higher yolk sac/chick weight ratio was observed for eggs of 41 week-old breeder hens and for eggs incubated at lower RAH (48\%). Chicks hatched from eggs of 41 to 56 week-old breeder hens had the highest heart weight/chick weight ratio.
\end{abstract}

Keywords: breeder hen, relative air humidity, age of breeder hen, incubation, yield

\section{INTRODUÇÃO}

As modificações na estrutura do ovo com o aumento da idade da matriz influenciam o rendimento de incubação. Ovos produzidos por matrizes velhas freqüentemente são maiores e têm a casca mais fina e com maior número de poros. O inverso acontece com os ovos produzidos por matrizes jovens, que são menores, com casca de maior espessura e menor quantidade de poros (Wilson, 1991; McLoughlin e Gous, 2000; Ribeiro et al., 2007).

A água atravessa os poros da casca movendo-se sempre do ponto mais úmido, que normalmente é o interior do ovo, para o ponto mais seco, o ambiente. Por esse motivo, a umidade em volta dos ovos férteis deve ser controlada para

Recebido em 23 de agosto de 2007

Aceito em 7 de abril de 2008

*Autor para correspondência (corresponding author)

E-mail: silvana@vet.ufmg.br

Apoio: FAPEMIG 
assegurar desenvolvimento adequado dos embriões (Tullett, 1990; Deeming, 1995; Decuypere, 2001).

À medida que aumenta a idade da matriz, aumenta a capacidade da casca em permitir as trocas de gases e vapor de água entre o embrião e o meio ambiente. Essa capacidade está relacionada diretamente com o número e as dimensões dos poros e com a espessura ou resistência da casca, além de se relacionar também com as condições ambientais da incubadora (Tullett, 1990; Campo e Ruano, 1995; Brake, 1996; Santos, 2003).

Quando a umidade relativa do ar na incubadora (URI) for muito baixa, haverá perda excessiva de umidade dos embriões, prejudicando a eclosão e resultando em pintos pequenos e desidratados. Por outro lado, se a URI for muito alta, os embriões tendem a eclodir precocemente, e com freqüência se apresentam molhados, podendo também ocorrer albúmen residual (Taylor, 1999; Salazar, 2000; Decuypere et al., 2003).

French e Tullett (1991) sugeriram que, para a obtenção de melhores rendimentos de incubação, é possível ajustar a URI baseando se na idade da matriz pesada. Vick et al. (1993) pesquisaram os efeitos de dois níveis de URI (50 e 58\%) sobre a eclodibilidade de ovos de matrizes pesadas durante o período de 28 até 64 semanas de idade e concluíram que há tendência de os ovos de matrizes mais jovens terem melhor taxa de eclosão e menor mortalidade embrionária precoce com URI mais baixa (50\%). Os ovos incubados com 58\% de URI apresentaram melhores taxas de eclodibilidade e menores índices de mortalidade embrionária tardia em matrizes a partir de 60 semanas de idade.

Buhr (1995) avaliou os efeitos da idade da matriz leve e da URI sobre a perda de peso dos ovos de um a 18 dias de incubação e sobre a taxa de eclosão e concluiu que, independente da idade da matriz, a perda de peso do ovo é maior quanto menor for a URI, sendo que os ovos de reprodutoras velhas perdem mais peso quando comparados com os ovos de reprodutoras novas. Quanto à eclodibilidade, o autor concluiu que ovos de matrizes novas devem ser incubados com URI mais baixa (55\%).
A variação no peso dos pintos à eclosão pode ser influenciada pelo peso do ovo antes da incubação e pela perda de peso durante a incubação. Portanto, ovos de matrizes mais velhas, que são mais pesados quando comparados aos das galinhas mais novas, produzem pintos mais pesados (Vieira e Moran Jr., 1998; Bruzual et al., 2000; Peebles et al., 2001; Ribeiro et al., 2007).

Vieira e Moran Jr. (1998) observaram que os pintos produzidos por matrizes mais velhas apresentaram maior peso corporal e maior peso de saco vitelino quando comparados com os pintos das matrizes mais novas e que, apesar de os ovos das matrizes mais velhas terem sido mais pesados e com maior peso de saco vitelino, não foram observadas diferenças significativas na relação peso saco vitelino/peso pinto. Porém, Maiorka et al. (2004), avaliando a relação peso saco vitelino/peso do pinto nos descendentes de matrizes pesadas com 30 e 60 semanas de idade, encontraram maior relação $(21,5 \%)$ nos pintos das matrizes mais velhas, quando comparadas com pintos das matrizes mais novas $(18,2 \%)$.

Luquetti et al. (2004) estudaram a influência da idade da matriz, no peso do pinto à eclosão e no peso do coração, e concluíram que as variáveis estudadas apresentaram aumento de peso absoluto à medida que aumentou a idade da matriz. Segundo Wineland e Christensen (2003), não foram observados efeitos dos níveis de URI sobre a relação peso do coração/peso do pinto.

Os objetivos deste trabalho foram avaliar os efeitos da URI e da idade da matriz leve sobre a perda de peso do ovo, a taxa de eclosão, o peso dos pintos à eclosão, a relação peso do pinto/peso do ovo e o peso absoluto do coração e do saco vitelino e a relação destes dois órgãos com o peso do pinto ao nascer.

\section{MATERIAL E MÉTODOS}

Foram utilizados 10.836 ovos (3612 ovos para cada idade) de matrizes leves da linhagem Lohmann LSL. Todos os ovos foram produzidos no mesmo dia e utilizados somente após um dia de armazenamento, para que não houvesse efeitos prejudiciais ao embrião (Fiúza et al., 2006). Foi realizada a seleção dos ovos, eliminando os ovos não incubáveis (sujos, trincados, quebrados, pequenos, com duas gemas e deformados). Após a seleção, os ovos foram 
classificados, estabelecendo-se uma categoria de peso para cada idade de matriz. As categorias de peso foram de 54,5 a 57,0g; 59,5 a $61,0 \mathrm{~g}$ e de 59,5 a $61,5 \mathrm{~g}$ para os ovos das matrizes com 26, 41 e 56 semanas de idade, respectivamente. Em seguida, os ovos foram colocados em bandejas próprias para incubação (cada bandeja foi considerada uma repetição), com capacidade para 86 ovos cada. Nessas condições, os ovos permaneceram na sala de armazenamento até o dia da incubação.

Os tratamentos foram definidos pela idade das matrizes e pelos níveis de URI, da seguinte maneira: ovos de matrizes com 26 semanas de idade, incubados com 48,0\% de URI; ovos de matrizes com 41 semanas de idade, incubados com $48,0 \%$ de URI; ovos de matrizes com 56 semanas de idade, incubados com $48,0 \%$ de URI; ovos de matrizes com 26 semanas de idade, incubados com 56,0\% de URI; ovos de matrizes com 41 semanas de idade, incubados com 56,0\% de URI; ovos de matrizes com 56 semanas de idade, incubados com 56,0\% de URI; ovos de matrizes com 26 semanas de idade, incubados com $64,0 \%$ de URI; ovos de matrizes com 41 semanas de idade, incubados com $64,0 \%$ de URI; ovos de matrizes com 56 semanas de idade, incubados com $64,0 \%$ de URI.

Foram utilizadas três incubadoras ${ }^{1}$, com capacidade para 19.264 ovos cada, que se localizavam na mesma sala de incubação. As três máquinas de incubação tiveram seus termostatos regulados para manter constante a temperatura em $37,2^{\circ} \mathrm{C}\left(99^{\circ} \mathrm{F}\right)$. A única diferença entre as incubadoras foi a temperatura do termômetro de bulbo úmido, cujo termostato foi regulado para $27,8^{\circ} \mathrm{C}\left(82^{\circ} \mathrm{F}\right), 29,4^{\circ} \mathrm{C}\left(85^{\circ} \mathrm{F}\right)$ e $31,1^{\circ} \mathrm{C}\left(88^{\circ} \mathrm{F}\right)$, correspondendo aos teores de URI iguais a $48 \%$, $56 \%$ e $64 \%$, respectivamente. Antes da entrada dos carrinhos nas incubadoras, todas as bandejas com os ovos do experimento foram pesadas individualmente. Cada carrinho foi colocado na mesma posição em cada uma das três incubadoras.

Os ovos do experimento ocuparam três bandejas em cada andar do carrinho de incubação. As bandejas foram distribuídas de tal forma que cada andar tivesse uma bandeja de ovos originados de cada lote de matriz, ou seja, uma

${ }^{1}$ Casp M57 RE - São Paulo, Brasil. repetição de cada idade da matriz. No momento da transferência para o nascedouro, todas as bandejas foram novamente pesadas individualmente. Após a pesagem, os ovos foram transferidos para bandejas de eclosão, identificadas de acordo com os tratamentos. Os pintos nascidos foram retirados das bandejas e colocados em caixas identificadas de acordo com os tratamentos e de repetições. $\mathrm{O}$ número de ovos não eclodidos foi registrado.

Foram determinadas: a perda de peso dos ovos, no momento em que foram transferidos da incubadora para o nascedouro; a taxa de eclosão total e a relação percentual do peso do pinto/peso do ovo.

Após o nascimento, foi realizada ao acaso a coleta de dois pintos de cada uma das 14 repetições de cada tratamento, totalizando uma amostra de 28 pintos por tratamento. Esses pintos foram sacrificados para a retirada do coração e do saco vitelino. Além dos dados de peso absoluto, foram avaliados também os dados referentes à relação percentual desses órgãos com o peso dos pintos.

Para a avaliação do rendimento de incubação (perda de peso do ovo, taxa de eclosão, peso dos pintos à eclosão, relação peso do pinto/peso do ovo), o delineamento experimental foi em blocos ao acaso no arranjo em parcelas subdivididas. $\mathrm{O}$ fator da parcela foi a URI (três níveis), e a subparcela foi a idade da matriz (três idades). Os blocos foram constituídos pelos andares dos carrinhos de incubação, em que cada andar continha uma repetição de cada idade da matriz. Os nove tratamentos foram constituídos por 14 repetições com 86 ovos cada (bandeja de incubação). Para a avaliação do peso absoluto do coração e do saco vitelino e a relação percentual desses órgãos com o peso do pinto, o delineamento experimental foi o mesmo utilizado para o rendimento de incubação, sendo, nesse caso, cada pinto considerado uma repetição. As diferenças entre as médias foram avaliadas pelo teste Student-Newman-Keuls (SNK), segundo Sampaio (2002).

\section{RESULTADOS E DISCUSSÃO}

Os resultados de perda de peso dos ovos durante a incubação se encontram na Tab. 1. Em relação à idade da matriz, a porcentagem de perda de 
peso dos ovos foi crescente com o aumento da idade $\quad(\mathrm{P}<0,05)$. Segundo Brake (1996), McLoughlin e Gous (2000) e Santos (2003), ocorre perda de peso linear de acordo com o aumento da idade das matrizes. Campo e Ruano (1995) concluíram que a perda de peso dos ovos foi inversamente proporcional à espessura da casca e diretamente proporcional ao número de poros existentes na mesma, e, como a qualidade da casca do ovo diminui com o aumento da idade da matriz, essa característica pode ser responsável pela maior taxa de perda de peso dos ovos das matrizes mais velhas obtidas neste experimento.

Tabela 1. Valores médios de perda de peso dos ovos durante o período de incubação (\%) de acordo com a umidade relativa do ar e a idade das aves

\begin{tabular}{lcccc}
\hline \multirow{2}{*}{ Idade } & \multicolumn{3}{c}{ Umidade relativa do ar $(\%)$} & \multirow{2}{*}{ Média } \\
\cline { 2 - 4 } & 48 & 56 & 64 & $12,11 \mathrm{c}$ \\
26 & 13,16 & 11,97 & 11,20 & $13,94 \mathrm{~b}$ \\
56 & 15,60 & 13,61 & 12,60 & $14,93 \mathrm{a}$ \\
Média & 16,77 & 14,62 & 13,39 & \\
\hline
\end{tabular}

Médias seguidas de letras distintas minúsculas na coluna e maiúsculas na linha diferem entre si pelo teste SNK $(\mathrm{P} \leq 0,05)$.

$\mathrm{CV}=2,8 \%$.

Foi observado também, independentemente da idade da matriz, maior perda de peso dos ovos à medida que a URI diminuiu. Resultados semelhantes foram encontrados por Vick et al. (1993), Deeming (1995), Buhr (1995) e Santos (2003). Tullett (1990) e Decuypere et al. (2003) justificaram que a água atravessa os poros da casca do ponto mais úmido para o ponto mais seco. Por isso, quanto mais úmido o ar em volta do ovo, menor será a sua taxa de evaporação.

Os valores das taxas de eclosão em relação ao número de ovos incubados se encontram na Tab.
2. As menores taxas de eclosão foram obtidas com os ovos das matrizes mais velhas (56 semanas), independente da URI $(\mathrm{P} \leq 0,05)$, e as melhores taxas de eclosão ocorreram quando os ovos foram submetidos à URI de $56 \%(\mathrm{P} \leq 0,05)$. Segundo Taylor (1999), Salazar (2000) e Decuypere et al. (2003), a baixa URI torna possível a perda excessiva de umidade nos embriões, prejudicando os nascimentos, e a alta URI, na incubação, pode ocasionar a baixa perda de umidade nos embriões, diminuindo o tamanho da câmara de ar do ovo e comprometendo o desenvolvimento dos mesmos.

Tabela 2. Taxa de eclosão total em relação aos ovos incubados (\%) de acordo com a umidade relativa do ar e a idade das aves

\begin{tabular}{lcccc}
\hline \multirow{2}{*}{ Idade } & \multicolumn{3}{c}{ Umidade relativa do ar (\%) } & \multirow{2}{*}{ Média } \\
\cline { 2 - 4 } & 48 & 56 & 64 & $79,84 \mathrm{a}$ \\
46 & 78,82 & 85,96 & 74,75 & $80,65 \mathrm{a}$ \\
56 & 80,65 & 84,80 & 76,49 & $69,85 \mathrm{~b}$ \\
Média & 66,45 & 76,33 & 66,78 & \\
\hline
\end{tabular}

Médias seguidas de letras distintas minúsculas na coluna e maiúsculas na linha diferem entre si pelo teste SNK $(\mathrm{P} \leq 0,05)$.

$\mathrm{CV}=6,9 \%$.

Os pesos médios dos pintos encontram-se na Tab. 3. Os maiores pesos de pintos foram atingidos com os ovos das aves com 41 semanas de idade, seguidos das aves com 56 semanas e, por último, das aves com 26 semanas, independente da umidade da incubadora
$(\mathrm{P} \leq 0,05)$. De acordo com Tullett (1990), a variação no peso dos pintos à eclosão pode ser influenciada pelo peso do ovo antes da incubação e pela perda de peso durante a incubação. Os ovos das aves com 41 semanas de idade tiveram perda de peso menor quando comparada aos 
tratamentos com matrizes de 56 semanas $(\mathrm{P} \leq 0,05)$. O peso dos pintos descendentes das aves mais jovens (26 semanas) foi significativamente menor $(\mathrm{P} \leq 0,05)$ que os descendentes de matrizes com idades mais elevadas, semelhante ao observado por Vieira e
Moran Jr. et al. (1998), Bruzual et al. (2000), Peebles et al. (2001) e Luquetti et al. (2004).

Em relação aos efeitos da URI, os maiores pesos dos pintos foram encontrados quando os ovos foram incubados com $64 \%$ de URI. Os pesos dos pintos nos níveis de 48 e $56 \%$ de URI não foram diferentes entre si $(\mathrm{P}>0,05)$ independentemente da idade da matriz.

Tabela 3. Peso médio dos pintos em gramas de acordo com a umidade relativa do ar e a idade das aves.

\begin{tabular}{lllll}
\hline \multirow{2}{*}{ Idade } & \multicolumn{3}{c}{ Umidade relativa do ar (\%) } & \multirow{2}{*}{ Média } \\
\cline { 2 - 4 } & 48 & 56 & 64 & $37,41 \mathrm{c}$ \\
\hline 26 & 37,24 & 37,50 & 37,49 & $40,27 \mathrm{a}$ \\
41 & 40,11 & 39,63 & 41,06 & $39,37 \mathrm{~b}$ \\
56 & 39,51 & 38,98 & 39,61 & \\
\hline
\end{tabular}

Médias seguidas de letras distintas minúsculas na coluna e maiúsculas na linha diferem entre si pelo teste SNK $(\mathrm{P} \leq 0,05)$.

$\mathrm{C} \overline{\mathrm{V}}=2,9 \%$.

A relação peso do pinto/peso do ovo (Tab. 4) foi menor no tratamento com 56 semanas de idade, independentemente da URI $(\mathrm{P} \leq 0,05)$. Esse comportamento sugere que a perda de peso dos ovos ocorrida durante o período de incubação foi responsável pela menor relação peso do pinto/peso do ovo. Luquetti et al. (2004) encontraram maior relação peso do pinto/peso do ovo para matrizes pesadas com 60 semanas quando comparados às idades de 30 e 45 semanas.
Em relação à URI, independente da idade da matriz, o nível de $64 \%$, em que os ovos perderam menor peso, revelou relação peso do pinto/peso do ovo significativamente maior $(\mathrm{P} \leq 0,05)$ quando comparada à relação daqueles que foram incubados com as umidades relativas de 48 e $56 \%$ e entre estas não foi verificada diferença $(\mathrm{P}>0,05)$. Os valores da relação peso do pinto/peso do ovo obtidos nesta pesquisa assemelham-se às informações obtidas de Wilson (1991), que considera que essa relação corresponde a $68 \%$ do peso inicial do ovo.

Tabela 4. Relação peso do pinto/peso do ovo de acordo com a umidade relativa do ar e a idade das aves

\begin{tabular}{lllll}
\hline \multirow{2}{*}{ Idade } & \multicolumn{3}{c}{ Umidade relativa do ar $(\%)$} & \multirow{2}{*}{ Média } \\
\cline { 2 - 4 } & 48 & 56 & 64 & $68,78 \mathrm{a}$ \\
46 & 68,65 & 68,36 & 69,32 & $68,84 \mathrm{a}$ \\
56 & 67,84 & 68,40 & 70,28 & $66,63 \mathrm{~b}$ \\
Média & 65,11 & 66,80 & 67,97 & \\
\hline
\end{tabular}

Médias seguidas de letras distintas minúsculas na coluna e maiúsculas na linha diferem entre si pelo teste SNK $(\mathrm{P} \leq 0,05)$.

$\mathrm{CV}=2,8 \%$.

Os valores relativos ao peso absoluto do saco vitelino e à relação peso saco vitelino/peso do pinto são apresentados nas Tab. 5 e 6 , respectivamente. Os pintos das matrizes com 41 semanas de idade apresentaram o maior peso de saco vitelino, independentemente da URI $(\mathrm{P} \leq 0,05)$, sendo que os pesos dos sacos vitelino dos pintos descendentes das matrizes com 26 e
56 semanas de idade foram semelhantes entre si $(\mathrm{P}>0,05)$. Independentemente da URI, a relação peso saco vitelino/peso do pinto foi significativamente menor $(\mathrm{P} \leq 0,05)$ para os ovos de matrizes de 56 semanas de idade, sendo que, nos pintos originados das matrizes com 26 e 41 semanas, não foram observadas diferenças $(\mathrm{P}>0,05)$. 
Tabela 5. Peso médio absoluto do saco vitelino em gramas de acordo com a umidade relativa do ar e a idade das aves

\begin{tabular}{llcll}
\hline \multirow{2}{*}{ Idade } & \multicolumn{3}{c}{ Umidade relativa do ar (\%) } & \multirow{2}{*}{ Média } \\
\cline { 2 - 4 } & 48 & 56 & 64 & \\
\hline 26 & 5,39 & 4,94 & 4,95 & $5,09 \mathrm{~b}$ \\
41 & 5,57 & 5,46 & 5,45 & $5,49 \mathrm{a}$ \\
56 & 5,34 & 4,85 & 4,82 & $5,00 \mathrm{~b}$ \\
Média & $5,43 \mathrm{~A}$ & $5,09 \mathrm{~B}$ & $5,07 \mathrm{~B}$ & \\
\hline
\end{tabular}

Médias seguidas de letras distintas minúsculas na coluna e maiúsculas na linha diferem entre si pelo teste SNK $(\mathrm{P} \leq 0,05)$.

$\mathrm{CV}=14,7 \%$

Independentemente da idade da matriz, o peso absoluto do saco vitelino e a relação peso saco vitelino/peso do pinto com $48 \%$ de URI foram mais altos que nos demais níveis de URI $(\mathrm{P} \leq 0,05)$. Entre as umidades de 56 e $64 \%$ não foram observadas diferenças $(\mathrm{P}>0,05)$. A maior relação saco vitelino/peso do pinto foi observada com utilização da URI de $48 \%(\mathrm{P} \leq 0,05)$, quando comparada com os tratamentos em que foram utilizadas as URI de 56 e $64 \%$, as quais foram semelhantes entre si $(\mathrm{P}>0,05)$.

Tabela 6. Relação peso do saco vitelino/peso do pinto (\%) de acordo com a umidade relativa do ar e a idade das aves

\begin{tabular}{lcccc}
\hline \multirow{2}{*}{ Idade } & \multicolumn{3}{c}{ Umidade relativa do ar $(\%)$} & \multirow{2}{*}{ Média } \\
\cline { 2 - 4 } & 48 & 56 & 64 & $13,93 \mathrm{a}$ \\
26 & 14,80 & 13,60 & 13,42 & $13,92 \mathrm{a}$ \\
56 & 14,30 & 13,95 & 13,53 & $13,03 \mathrm{~b}$ \\
Média & 13,89 & 12,68 & 11,10 & \\
\hline
\end{tabular}

Médias seguidas de letras distintas minúsculas na coluna e maiúsculas na linha diferem entre si pelo teste SNK $(\mathrm{P} \leq 0,05)$.

$\mathrm{CV}=12,7 \%$.

Nas Tab. 7 e 8, são apresentados os resultados dos pesos absolutos do coração e a relação peso do coração/peso do pinto, respectivamente. Foi observado efeito da idade da matriz sobre o peso absoluto do coração, e os pintos das matrizes com 26 semanas tiveram pesos significativamente menores $(\mathrm{P} \leq 0,05)$. Os pintos das matrizes, com idades de 41 e 56 semanas, foram semelhantes entre si. Estes resultados assemelham-se aos encontrados por Luquetti et al. (2004), que verificaram acréscimo no peso absoluto do coração à medida que aumentou a idade da matriz pesada.

Tabela 7. Peso absoluto do coração em gramas de acordo com a umidade relativa do ar e a idade das aves

\begin{tabular}{lcccc}
\hline \multirow{2}{*}{ Idade } & \multicolumn{3}{c}{ Umidade relativa do ar $(\%)$} & \multirow{2}{*}{ Média } \\
\cline { 2 - 4 } & 48 & 56 & 64 & $0,28 \mathrm{~b}$ \\
46 & 0,28 & 0,28 & 0,29 & $0,31 \mathrm{a}$ \\
56 & 0,31 & 0,30 & 0,32 & $0,31 \mathrm{a}$ \\
Média & 0,32 & 0,30 & 0,31 & \\
\hline
\end{tabular}

Médias seguidas de letras distintas na coluna diferem entre si pelo teste $\mathrm{SNK}(\mathrm{P} \leq 0,05)$.

$\mathrm{CV}=10,9 \%$

A relação peso do coração/peso do pinto também foi influenciada pela idade da matriz, sendo que a relação foi maior $(\mathrm{P} \leq 0,05)$ nos pintos descendentes de matrizes com 56 semanas, e os valores encontrados nos pintos originados de matrizes com 26 e 41 semanas foram semelhantes entre si. Não foram observados efeitos significativos da URI sobre o peso absoluto e a relação peso do coração/peso do pinto $(\mathrm{P}>0,05)$. Estes resultados assemelham-se aos encontrados por Wineland e Christensen (2003), que não observaram efeito significativo de níveis de umidade relativa na incubação de ovos de matrizes pesadas sobre a relação peso do coração/peso do pinto. 
Efeitos da umidade relativa do ar...

Tabela 8. Relação peso do coração/peso do pinto de acordo com a umidade relativa do ar e a idade das aves

\begin{tabular}{lcccc}
\hline \multirow{2}{*}{ Idade } & \multicolumn{3}{c}{ Umidade relativa do ar (\%) } & \multirow{2}{*}{ Média } \\
\cline { 2 - 4 } & 48 & 56 & 64 & $0,78 \mathrm{~b}$ \\
41 & 0,78 & 0,77 & 0,78 & $0,78 \mathrm{~b}$ \\
56 & 0,79 & 0,75 & 0,80 & $0,81 \mathrm{a}$ \\
Média & 0,82 & 0,79 & 0,81 & \\
\hline
\end{tabular}

Médias seguidas de letras distintas na coluna diferem entre si pelo teste $\mathrm{SNK}(\mathrm{P} \leq 0,05)$.

$\mathrm{CV}=10,0 \%$.

\section{CONCLUSÕES}

A perda de peso do ovo é maior à medida que diminui a umidade relativa do ar na incubadora ou à medida que aumenta a idade da matriz.

\section{REFERÊNCIAS BIBLIOGRÁFICAS}

BRAKE, J.T. Optimización del almacenaje de huevos fértiles. Avic. Prof., v.14, p.26-31, 1996.

BRUZUAL, J.J.; PEAK, S.D.; BRAKE, J. et al. Effects of relative humidity during incubation on hatchability and body weight of broiler chicks from younger breeder flocks. Poult. Sci., v.79, p.827-830, 2000.

BUHR, R.J. Incubation relative humidity effects on allantoic fluid volume and hatchability. Poult. Sci., v.74, p.874-884, 1995.

CAMPO, J.L.; RUANO, R.G. Differences between hatched and non-hatched eggs for weight loss during incubation, shell color, and shape index. Archiv für Geflügelk., v.59, p.310313, 1995.

DECUYPERE, E.; MALHEIROS, R.D.; MORAES, V.M.B. et al. Fisiologia do embrião. In: MACARI, M. e GONZALES, E. (Eds). Manejo da incubação. 2.ed. Campinas: FACTA, 2003. p.65-94.

DECUYPERE, E.; TONA, K.; BRUGGEMAN, V. et al. The day-old chick: A crucial hinge between breeders and broilers. World's Poult. Sci. J., v.57, p.127-138, 2001.

FIÚZA, M.A.; LARA, L.J.C.; AGUILAR, C.A.L. et al. Efeitos das condições ambientais no período entre a postura e o armazenamento de ovos de matrizes pesadas sobre o rendimento de incubação. Arq. Bras. Med. Vet. Zootec., v.58, p.408-413, 2006.
FRENCH, N.A.; TULLETT, S.G. Variation in the eggs of various poultry species. In: TULLETT, S.G. (Ed.). Avian incubation. London: Butterworth-Heinemann, 1991. p.59-77.

LUQUETTI, B.C.; GONZALEZ, E.; BRUNO, L.D.G. et al. Egg traits and physiological neonatal chick parameters from broiler breeder at different ages. Rev. Bras. Cienc. Avic., v.6, p.1317, 2004.

MAIORKA, A. Efeitos da idade da matriz, do jejum, da energia da ração e da glutamina sobre o desenvolvimento da mucosa intestinal $e$ atividade enzimática do pâncreas de pintos de corte. 2002. 103f. Tese (Doutorado) - Faculdade de Ciências Agrárias e Veterinárias, Universidade Estadual Paulista, Jaboticabal.

MCLOUGHLIN, L.; GOUS, R.M. Efecto del tamaño del huevo en el crecimiento pre y post natal de pollitos de engorde. Avic. Prof., v.18, p.24-29, 2000.

PEEBLES, E.D.; BURNHAM, M.R.; GARDNER, C.W. et al. Effects of incubational humidity and hen age on embryo composition in broiler hatching eggs from young breeders. Poult. Sci., v.80, p.1299-1304, 2001.

RIBEIRO, B.R.C.; LARA, L.J.C.; BAIÃO, N.C. et al. Efeito do nível de ácido linoléico na ração de matrizes pesadas sobre o peso, composição e eclosão dos ovos. Arq. Bras. Med. Vet. Zootec., v.59, p.789-796, 2007.

SALAZAR, A.I. El proceso de incubación. Avic. Prof., v.18, p.26-30, 2000.

SAMPAIO, I.B.M. Estatística aplicada à experimentação animal. 2.ed., Belo Horizonte: FEPMVZ, 2002. 244p.

SANTOS, G.C.F. Efeito de linhagem e idade de reprodutoras pesadas e leves sobre a perda de umidade de ovos incubáveis aos 18 dias de 
incubação, submetidos a diferentes percentuais de umidade relativa. 2003. 17f. Monografia (Pósgraduação lato-sensu em Ciências Aviárias) Faculdade de Medicina Veterinária, Universidade Federal de Uberlândia, Uberlândia.

TAYLOR, G. Understanding high yield broiler incubation. Zootec. Int., v.22, p.32-36, 1999.

TULLETT, S.G. Science and the art of incubation. Poult. Sci., v.69, p.1-15, 1990.

VICK, S.V.; BRAKE, J.; WALSH, T.J. Relationship of incubator humidity and flock age to hatchability of broiler hatching eggs. Poult. Sci., v.72, p.251-258, 1993.
VIEIRA, S.L.; MORAN JR, E.T. Eggs and chicks from broiler breeders of extremely different age. J. Appl. Poult. Res., v.7, p.372376, 1998.

WILSON, H.R. Interrelationships of egg size, chick size, posthatching growth and hatchability. World's Poult. Sci. J., v.47, p.5-20, 1991.

WINELAND, M.J.; CHRISTENSEN, V.L. Effect of egg moisture loss upon the embryo and growing chick. Int. Hatch. Pract., v.17, p.17, 2003. 